\title{
De Quervain's tenosynovitis in a child
}

\section{Senthil Kumar Palaniappan ${ }^{1 *}$, Kamalanathan Kulandivelu ${ }^{2}$, Kannadhasan Ramadhas ${ }^{3}$}

\author{
${ }^{1}$ Masonic Medical Centre for Children, Coimbatore, Tamil Nadu, India \\ ${ }^{2}$ Department of Orthopaedics, PSG Institute of Medical Sciences and Research, Coimbatore, Tamil Nadu, India \\ ${ }^{3}$ Government Medical College and ESI Hospital, Coimbatore, Tamil Nadu, India
}

\author{
Received: 03 March 2021 \\ Revised: 04 April 2021 \\ Accepted: 05 April 2021

\section{*Correspondence: \\ Dr. Senthil Kumar Palaniappan,} \\ E-mail: drvpsk@rediffmail.com
}

Copyright: (c) the author(s), publisher and licensee Medip Academy. This is an open-access article distributed under the terms of the Creative Commons Attribution Non-Commercial License, which permits unrestricted non-commercial use, distribution, and reproduction in any medium, provided the original work is properly cited.

\begin{abstract}
De Quervain's tenosynovitis is common in adults but extremely rare in children. Current investigation report a 9 year old girl who was diagnosed to have De Quervain's tenosynovitis presented with pain over lateral end of right wrist with very minimal swelling lasted for 10 days. Clinical and ultrasonographic examinations contributed to the diagnosis. Overuse of mobile phone by this child resulting in repetitive movements and strain injuries of the thumb and wrist contributed to the development of tenosynovitis of the tendons of thumb which is reported in literature. Current case is reported to create awareness among pediatricians about this rare condition which may become common in the future.
\end{abstract}

Keywords: De Quervain tenosynovitis, Children, Mobile phone

\section{INTRODUCTION}

Etiology for sub-acute wrist pain in children are many which includes fracture, inflammation involving tendons, joints or other soft tissues and rarely neoplasm. ${ }^{1}$ Inflammation involving the tendons also known as tenosynovitis is very rare in children. ${ }^{2}$ It is due to an overuse injury associated with activities involving the corresponding tendons for prolonged periods. Activities contributing to inflammation include typing, lifting and manipulation. ${ }^{3}$ We report a 9 years old female child who presented with pain and swelling at lateral end of right wrist and was diagnosed to have De Quervain's tenosynovitis which is very rare in children.

\section{CASE REPORT}

Nine years old female child was brought with complaints of pain and swelling involving right wrist for 10 days. Pain was insidious in onset, gradually increasing and was felt while moving the right wrist and palpating the radial side of right wrist. She denied a history of trauma. She didn't have fever, rash and joint pain. Her growth and development were normal. Family members were in good health.

On examination, she was alert, active with stable vitals. Examination of right wrist showed a cord like swelling present over the radial styloid and extended up to first carpo-metacarpal junction. There was no erythema over the swelling (Figure 1). On palpation, tenderness was present over radial styloid and over the swelling. There was painful limitation of movements involving abduction of thumb and ulnar and radial deviation of wrist. Other movements of wrist were normal. Blood counts and ESR were normal. Mantoux test was negative. Initially sprain and scaphoid fracture due to unremembered injury were considered. X-ray of the right hand was normal. Since Finkelstein's maneuver was positive, tenosynovitis was considered and ultrasound (USG) was done. USG showed 
increase in the hypoechoeic areas around the abductor pollicis longus (APL) and extensor pollicis brevis (EPB) tendons with increased vascularity suggestive of De Quervain's tenosynovitis (Figure 2). MRI of the wrist confirmed the above findings.

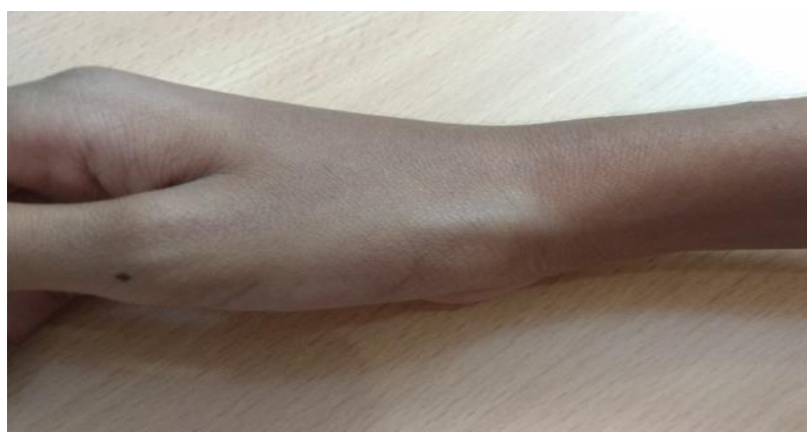

Figure 1: Swelling at the lateral end of right wrist.

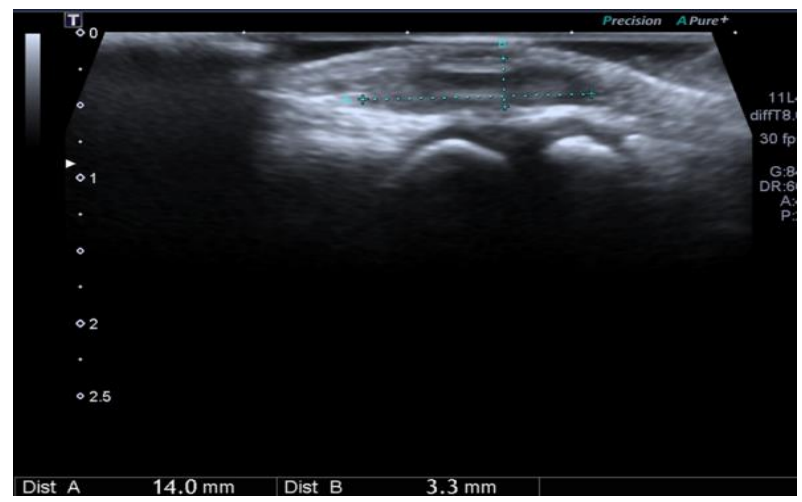

Figure 2: Increase in the hypoechoeic areas around the abductor pollicis longus tendon.

On probing into the history, mother revealed a history of excessive use of mobile phones (6-8 hours/day) for attending online classes, gaming and texting. Excessive use of mobile phone might have led to repeated micro trauma and strain injury of abductor pollicis longus (APL) and extensor pollicis brevis (EPB) tendon sresulting in tenosynovitis which was reported in literature. Child was managed with non-steroidal antiinflammatory drugs and strict rest to the right hand without immobilization. She showed remarkable improvement in two weeks of time with reduction of swelling and absence of pain while moving the thumb and wrist. Child was asked to come for regular follow up.

\section{DISCUSSION}

De Quervain's tenosynovitis (DQT) was first described in 1895 by Fritz De Quervain. ${ }^{4}$ It is common in adults but extremely rare in children. It is usually seen in pregnancy, rheumatoid arthritis and activities associated with repeated micro trauma to the first extensor compartment like golfing, piano playing, and carrying a child in the arms for prolonged periods..$^{5}$ Recent studies have shown a clear relation between texting with a phone and De Quervain's tenosynovitis. ${ }^{5-7}$ Our child was also using mobile phone for about 8 hours a day for online classes, games and texting. Only very few pediatric cases of De Quervain tenosynovitis were reported in literature. ${ }^{2}$

DQT is an entrapment tenosynovitis of the first extensor compartment containing APL and EPB. ${ }^{2}$ The exact etiology of de Quervain's tendinopathy is not well understood. It was often attributed to repetitive activities and postures that maintain the thumb in extension and abduction. $^{2}$

Histopathology shows myxoid degeneration rather than inflammation with fibrous tissue deposition and increased perfusion, causing tendon sheath thickening. ${ }^{8}$ It usually presents with sub-acute pain and swelling at the radial side of the wrist especially with thumb and wrist movements.

The pathognomonic of de Quervain's disease is the positive Finkelstein test which is performed by grasping the patient's thumb and quickly deviating the hand and wrist ulnar side resulting in pain. Other maneuvers used are Eichhoff's test and WHAT test with varying sensitivity and specificity. ${ }^{2}$

Diagnosis is essentially clinical with history and positive Finkelstein test. Radiographs are indicated only when fracture is suspected. Ultra sonogram of wrist and thumb is confirmatory which usually shows thickening of extensor retinacula and increased hypoechoeic areas surrounding the APL and EPB tendons with increased vascularity. ${ }^{9}$

MRI is useful to know about the anatomical variations of the tendons and extensor retinacula and prognostication. ${ }^{10}$

Most of the recommendations in the management are based on adult experiences which include antiinflammatory drugs, immobilization, local steroid injections in order and finally surgical release when medical management fails. ${ }^{2,3}$ Even though mobile phone usage by children is inevitable in modern days, they need to be monitored by their parents to avoid this kind of maladies.

\section{CONCLUSION}

Since texting and gaming in smart phones by children is increasing, De Quervain's tenosynovitis may emerge as a common problem even though it was very rare in children. Pediatricians should be aware to this association between the overuse of mobile phone and De Quervain's tenosynovitis when treating children with wrist pain.

\section{ACKNOWLEDGEMENTS}

Authors would like to thank Dr. Vidhya for helping in the collection of data. 
Funding: No funding sources

Conflict of interest: None declared

Ethical approval: Not required

\section{REFERENCES}

1. Shehab R, Mirabelli MH. Evaluation and diagnosis of wrist pain: a case-based approach. Am Fam Physician. 2013;87(8):568-73.

2. Traverso AM, Douek $P$, Schivo $D$, Bruyère $C$, Müller CT, Krähenbühl SM. De Quervain tenosynovitis in a 12-year-old child: a generation's disease?. J Orthop Surg Tech. 2015;1(2):29-32

3. Ilyas AM, Ast M, Schaffer AA, Thoder J. De quervain tenosynovitis of the wrist [published correction appears in J Am Acad Orthop Surg. 2008; 16(2):35A.

4. De Quervain F. On a form of chronic tendovaginitis by Dr. Fritz de Quervain in la Chaux-de-Fonds. 1895. Am J Orthop. 1997;26(9):641-4.

5. Ashurst JV, Turco DA, Lieb BE. Tenosynovitis caused by texting: an emerging disease. J Am Osteopath Assoc. 2010;110(5):294-6.

6. Baabdullah A, Bokhary D, Kabli Y, Saggaf O, Daiwali M, Hamdi A. The association between smartphone addiction and thumb/wrist pain: A crosssectional study. Medicine (Baltimore). 2020;99(10): e19124.

7. Ali M, Asim M, Danish SH, Ahmad F, Iqbal A, Hasan SD. Frequency of De Quervain's tenosynovitis and its association with SMS texting. Muscles Ligaments Tendons J. 2014;4(1):74-8.

8. Clarke MT, Lyall HA, Grant JW, Matthewson MH. The histopathology of de Quervain's disease. J Hand Surg Br. 1998;23(6):732-4.

9. McBain B, Rio E, Cook J, Grabinski R, Docking S. Diagnostic accuracy of imaging modalities in the detection of clinically diagnosed de Quervain's syndrome: a systematic review. Skeletal Radiol. 2019; 48(11):1715-21.

10. Goyal A, Srivastava DN, Ansari T. MRI in De Quervain Tenosynovitis: is making the diagnosis sufficient?. AJR Am J Roentgenol. 2018;210(3): W133-4.

Cite this article as: Palaniappan SK, Kulandivelu K, Ramadhas K. De Quervain's tenosynovitis in a child. Int J Contemp Pediatr 2021;8:935-7. 